\title{
Trio elétrico ou bandwagon? Um estudo das estratégias de tradução de referentes culturais em textos turísticos
}

\section{Trio elétrico or bandwagon? A study of translation strategies for cultural referents in tourist texts}

O Tio Sam está querendo conhecer a nossa batucada. Anda dizendo que o molho da baiana melhorou seu prato. Vai entrar no cuscuz, acarajé e abará. Na Casa Branca já dançou a batucada de ioiô, iaiá.

Assis Valente

Giovana Martins de Castro Marqueze*

\footnotetext{
* Mestra em Letras pela Universidade de São Paulo e professora temporária do programa de inglês da graduação em Letras do DLM/FFLCH, na mesma universidade.

E-mail: giovana.marchese@hotmail.com

TradTerm, São Paulo, v.37, n. 2, janeiro/2021, p. 671-699

Número Especial - Linguística de Corpus 
Resumo: Para que o fluxo de turistas estrangeiros que chegam ao Brasil tenha acesso a informações sobre os serviços oferecidos pelo setor turístico, textos turísticos são produzidos em larga escala e em diversos idiomas. Como é de se esperar, referentes culturais abundam nesses textos, sendo um desafio constante com o qual os tradutores devem lidar. Dessa forma, à luz da teoria funcionalista da tradução de Nord (1991, 1997) e de Reiss e Vermeer (1984) e com a Linguística de Corpus como metodologia, analisamos as traduções do português para o inglês de textos turísticos sobre o Brasil publicados pela EMBRATUR a fim de descobrir quais estratégias são empregadas na tradução de referentes culturais e se elas colaboram para o cumprimento do propósito desses textos na cultura-meta. As estratégias são descritas com base na lista de estratégias para tradução de referentes culturais proposta por Marco (2002).

Palavras-chave: Linguística de Corpus; Embratur; Tradução; Turismo; Funcionalismo.

Abstract: In order to familiarize travelers in Brazil with the services offered by the tourist sector, tourist texts are published in various different languages on full-scale. As one would expect, cultural referents abound in tourist texts, thus posing challenges with which translators must deal. Therefore, in the light of the functionalist approach to translation as expounded by Christiane Nord $(1991,1997)$ and by Reiss \& Vermeer (1984) and using Corpus Linguistics as our methodology, we analyzed the translations from Portuguese into English in the tourists texts about Brazil published by the Brazilian Tourist Board in order to detect what strategies are employed in the translation of cultural referents. Afterwards, we analyzed the adequacy of these strategies in serving the purpose of the target text. The strategies are described based on the list of translation techniques for cultural referents proposed by Marco (2002).

Keywords: Corpus Linguistics; Embratur; Translation; Tourism; Functionalism.

TradTerm, São Paulo, v.37, n. 2, janeiro/2021, p. 671-699

Número Especial - Linguística de Corpus www.revistas.usp.br/tradterm 


\section{Introdução}

A indústria do turismo é um mosaico composto por uma série de setores, dentre os quais destacamos o setor de transportes, o hoteleiro, o alimentício, o do entretenimento, o dos guias turísticos e o da tradução, sendo esses dois últimos os que nos interessam particularmente neste trabalho.

Responsáveis pelo sustento do turismo, se um desses setores falha, as consequências são sentidas como um todo. Ademais, crises diplomáticas, políticas e sanitárias também exercem um impacto direto na indústria turística. É o que ocorre atualmente com a crise do coronavírus. Já na primeira quinzena de março, o turismo no Brasil perdeu R\$ 2,2 bilhões, número preocupante para um setor responsável pelo sustento de sete milhões de brasileiros (ÁvILA 2020). A fim de reverter o impacto negativo dos prejuízos inevitáveis, a Embratur (Instituto Brasileiro de Turismo) tem criado campanhas para o público internacional, incentivando-o a visitar o Brasil depois que a crise passar ${ }^{1}$. Certamente, quando falamos de divulgação internacional, estamos falando de textos turísticos (sejam eles escritos ou orais) e de tradução.

Textos turísticos aqui são entendidos como qualquer texto publicado por uma organização pública ou privada com o intuito de fornecer informação a um possível visitante e anunciar um destino como uma cidade, um hotel, um restaurante etc., encorajando o público a visitá-lo (KELLY 1997). Representando um desafio para os tradutores, muitos desses textos partem da arquitetura, passam pela história da arte, geografia e esportes em poucas páginas, nas quais abundam referentes culturais. Esses últimos são definidos por Snell-Hornby (1999: 115, tradução nossa) como "elementos da vida diária, história, cultura ou instituições de determinada comunidade que não existem da mesma forma em outras"2. Como se referem a conceitos próprios de uma comunidade, vertêlos para o texto-meta pode trazer algumas dificuldades para o tradutor,

\footnotetext{
1 Instituto Brasileiro do Turismo (org.). Campanha da Embratur "Brazil You Want It! We Got It!". 2020. Disponível em: http://www.embratur.gov.br/piembraturnew/opencms/salalmprensa/galeria_multimidia/galeria_video/arquivo/Campanha_da_Embra tur_Brazil_You_Want_It_We_Got_It.html. Acesso em: 28 abr. 2020.

2 "Elements from the daily life, history, culture or institutions of a given community which do not exist as such in other communities."
}

TradTerm, São Paulo, v.37, n. 2, janeiro/2021, p. 671-699

Número Especial - Linguística de Corpus www.revistas.usp.br/tradterm 
principalmente no caso de textos turísticos, onde os referentes culturais servem de chamariz para o viajante em busca do exótico e do desconhecido.

Unindo a complexidade dos textos turísticos e de sua tradução à importância de uma divulgação de qualidade do Brasil como destino turístico internacional, nos foi de interesse investigar como a Embratur tem promovido o país no exterior. Nosso foco foram as traduções para o inglês dos textos turísticos produzidos pelo instituto e disponibilizados para download no site do Ministério do Turismo. O objetivo deste estudo foi o de investigar como referentes culturais brasileiros ${ }^{3}$ estavam sendo vertidos para esse idioma e fazer inferências sobre as estratégias de tradução empregadas, relacionandoas com o propósito a ser alcançado pelo texto-meta.

0 presente artigo está dividido em seis seções. A seção 2 contempla os desafios de tradução de textos turísticos e discorre sobre as estratégias de tradução de referentes culturais sob a luz da Teoria Funcionalista da Tradução. Tendo a Linguística de Corpus como aporte metodológico, detalhamos na seção 3 o levantamento dos termos a serem analisados e de suas traduções. A seção 4 é dedicada à discussão de alguns resultados deste estudo e, por fim, apresentamos nossas considerações finais na seção 5 . Na seção 6, o leitor encontrará as referências utilizadas neste trabalho.

\section{Desafios na tradução de textos turísticos}

Deveria ser opinião unânime sobre os textos turísticos que possuir uma linguagem clara é característica indispensável para que alcancem uma comunicação eficaz, já que são essenciais para que seja feita a ponte entre turistas e a cultura a ser visitada (MerkaJ 2013). Muñoz (2013), no entanto, observa que a clareza requerida nesses textos nem sempre está presente, uma vez que, por apresentarem uma linguagem não técnica, são vistos como textos de redação simples. Dessa forma, são negligenciados pelas próprias agências que os produzem. A autora explica que informações equivocadas, erros gramaticais e erros de grafia são alguns exemplos do que pode ser encontrado em textos turísticos mundo afora. Consequentemente, da mesma forma que a

\footnotetext{
${ }^{3}$ Destacamos que, neste estudo, lidamos apenas com referentes culturais lexicais.

TradTerm, São Paulo, v.37, n. 2, janeiro/2021, p. 671-699

Número Especial - Linguística de Corpus www. revistas.usp.br/tradterm
} 
redação dos textos-fonte é negligenciada por certas agências, seu processo de tradução também o será.

Pierini (2007) e Merkaj (2013) comentam que, justamente por acreditarem que os textos turísticos são "fáceis" de traduzir, já que possuem linguagem de cunho mais geral, as agências costumam contratar qualquer falante da língua-meta em vez de tradutores profissionais, o que geralmente resulta em um produto tanto de baixo custo como de baixa qualidade. Segundo as autoras, a "facilidade" atribuída a esses textos não passa de mera ilusão, posto que, como observado na introdução deste trabalho, a presença de termos de várias áreas do saber e seu vasto conteúdo cultural fazem dos textos turísticos uma complexa tarefa de tradução, que exigirá do tradutor não só o conhecimento dos idiomas envolvidos, mas também entendimento sobre a cultura-fonte e a cultura-meta ${ }^{4}$ para que, assim, saiba tomar as decisões de tradução mais adequadas ao trabalho sendo conduzido. Esse conhecimento, como sabemos, vem com treinamento e experiência.

Mas o que queremos dizer com "decisões de tradução mais adequadas"? A resposta para esta pergunta está um pouco mais adiante.

\subsection{Teoria funcionalista da tradução}

Até meados da década de 70, o princípio de fidelidade ao texto-fonte e a busca por equivalentes interlinguais eram os principais condutores do processo tradutório. O funcionalismo surge na Alemanha nessa época com, principalmente, Katharina Reiss e Hans J. Vermeer, como uma resposta a essa visão tradicionalista da tradução. Para os funcionalistas, o ato tradutório consiste em uma ação comunicativa determinada pelo seu propósito, denominado skopos (REISS; VERMEER 1996). De acordo com esse conceito, aplicase o princípio da funcionalidade: a função que a tradução terá na cultura-meta guiará o processo tradutório.

\footnotetext{
${ }^{4}$ Especificamente neste trabalho não lidamos com uma cultura-meta específica, posto que os materiais disponibilizados pela Embratur apresentam traduções somente para o inglês. Dessa forma, esses materiais traduzidos têm um público-alvo universal, ou seja, qualquer não falante do português que leia em inglês, seja ele canadense ou italiano, por exemplo.
}

TradTerm, São Paulo, v.37, n. 2, janeiro/2021, p. 671-699

Número Especial - Linguística de Corpus www.revistas.usp.br/tradterm 
Segundo Vermeer (1996), como toda ação, o ato tradutório carrega uma intenção, o que, para Nord (1997) pressupõe a existência do livre-arbítrio e de uma escolha entre, pelo menos, duas formas de comportamento, das quais apenas uma será a mais apropriada de acordo com o propósito pretendido. Esse propósito, definido por quem encomendou a tradução, é aquele que o produto tradutório terá na cultura-meta. Assim, de acordo com o Funcionalismo, não há uma única forma de se realizar uma tradução. O resultado final dependerá do objetivo a ser alcançado no texto-meta, o que oferece ao tradutor argumentos para que possa justificar suas escolhas durante o processo tradutório.

Reiss e Vermeer (1996) ainda alegam que a definição do propósito a ser alcançado no texto-meta dependerá de seus receptores finais e usam guias de viagem para exemplificar seu argumento: os guias que foram escritos originalmente para um público específico deverão passar por certas modificações ao serem traduzidos para outro público, já que as informações que esse último requer são distintas daquelas necessárias ao público original. Isso coloca o tradutor na tarefa de atender as expectativas do leitor-meta, exigindo do profissional, como vimos com Pierini (2007) e Merkaj (2013), não apenas o conhecimento dos idiomas envolvidos no processo tradutório, mas também da cultura para a qual se traduz.

No final da década de 80 , a noção de lealdade é introduzida no Funcionalismo por Christiane Nord. Diferentemente do conceito tradicional de fidelidade, o qual se preocupa com semelhanças linguísticas e estilísticas entre o texto-fonte e o texto-meta, a lealdade diz respeito às expectativas e intenções de todos os envolvidos no processo tradutório. Nord (1991) explica que, além do compromisso para com as situações comunicativas do texto-fonte e do texto-meta, o tradutor também tem um compromisso para com o iniciador da tradução (aquele que a encomenda) e seus leitores. Afinal, não podendo checar se o conteúdo do produto tradutório está em conformidade com suas expectativas, o iniciador da tradução e o receptor do texto-meta deverão confiar que o tradutor tenha conduzido um trabalho em concordância com o que the foi solicitado.

No Funcionalismo também estão inseridas as tipologias textuais de Reiss (1971), publicadas primeiramente entre 1968 e 1969. Em seu estudo, a autora

TradTerm, São Paulo, v.37, n. 2, janeiro/2021, p. 671-699 Número Especial - Linguística de Corpus www.revistas.usp.br/tradterm 
apresenta as três funções principais da linguagem à luz do modelo do psicólogo e linguista alemão Karl Buihler (1934), a saber: a representativa (textos do tipo informativo, como os manuais de instrução), a expressiva (textos expressivos, como os poemas) e a apelativa (textos operativos, como os anúncios publicitários).

Reiss (1971) explica que, comumente, um único texto apresenta uma combinação de funções textuais. No entanto, existe sempre aquela que é dominante. É fundamental, portanto, que o tradutor conheça as funções comunicativas de um texto dentro de um determinado propósito de tradução, já que elas apontam para o que deverá ser priorizado no processo tradutório (REISS; VERMEER 1996).

Os textos turísticos constituem um bom exemplo aqui, como ilustrado por Marqueze (2018): sua função dominante é a apelativa, uma vez que tentam convencer o leitor a visitar o local ou atração divulgados. No entanto, esses textos também são informativos, visto que trazem informações essenciais, como horários de funcionamento de atrações e tabela de conversão de medidas. Por último, os textos turísticos também são expressivos, pois as figuras de linguagem são frequentemente empregadas pelos autores para gerar uma resposta emocional positiva no leitor. Dessa forma, podemos dizer que, durante o processo tradutório, a atenção deve ser dada, primeiramente, à função apelativa dos textos turísticos, seguida por sua função informativa e finalmente, pela função expressiva (MARQUEZE 2018). Em outras palavras, as escolhas feitas pelo tradutor de textos turísticos devem ser guiadas pela necessidade de chamar a atenção do leitor-meta para o local divulgado, o que poderá significar uma mudança tanto na quantidade de informação veiculada pelo texto-meta como no estilo utilizado, os quais devem adequar-se à cultura para a qual o texto está sendo traduzido.

Alicerçadas na teoria funcionalista da tradução, a nossa próxima pergunta é: como, então, lidar com referentes culturais lexicais em textos turísticos? Para isso, definiremos na próxima subseção o conceito de referente cultural.

TradTerm, São Paulo, v.37, n. 2, janeiro/2021, p. 671-699 Número Especial - Linguística de Corpus www.revistas.usp.br/tradterm 


\subsection{Referentes culturais}

Abundantes em textos turísticos, os referentes culturais lexicais representam um grande desafio para o tradutor, cuja tarefa é transformar a cultura estrangeira em atrativos para um viajante que não tenha conhecimento sobre ela.

Com uma visão funcionalista da tradução, Florin (1993) explica que a maneira como o tradutor deverá lidar com os referentes culturais lexicais dependerá, primeiramente, da função do texto-meta na cultura de chegada, uma vez que, por serem típicos de uma cultura, raramente possuem equivalentes exatos em outro idioma. No caso dos textos turísticos, como vimos anteriormente, a função apelativa deve ter prioridade. Assim, os referentes culturais presentes nesses textos deverão ser apresentados de tal maneira que se tornem atrativos para o leitor-meta. Como a função representativa é secundária, o tradutor precisará dosar a quantidade de informações a serem transferidas do texto-fonte para o texto-meta. Uma sobrecarga ou insuficiência de informações poderá resultar, nas palavras de Kelly (1997), em quebra de comunicação, prejudicando, consequentemente, a função apelativa.

Um segundo ponto de atenção que o tradutor deve ter aqui, segundo Florin (1993), é o grau de familiaridade que o leitor-meta tem com a cultura que está sendo divulgada; afinal, alguns países compartilham dos mesmos referentes culturais. É o caso de pampas, bioma presente tanto no Brasil como na Argentina e no Uruguai. $O$ termo em questão, na tradução para o espanhol de um texto turístico sobre o Brasil que tenha como público-alvo os leitores desses países, poderá ser transferido para o texto-meta sem maiores explicações. Porém, se o mesmo termo estiver em um texto turístico sobre o Brasil cujo público-alvo são os leitores espanhóis, a pura transferência desse termo pode não ser suficiente para o entendimento do leitor-meta (MARQUEZE 2018).

Uma terceira particularidade da tradução de referentes culturais que Florin (1993) menciona é a sua importância na passagem a ser traduzida. Dessa forma, o tradutor deve avaliar se determinado referente cultural faz parte do centro de atenção do leitor-meta ou se constitui mero detalhe.

TradTerm, São Paulo, v.37, n. 2, janeiro/2021, p. 671-699 Número Especial - Linguística de Corpus www.revistas.usp.br/tradterm 
Um último aspecto da tradução de referentes culturais que Florin (1993) sugere que o tradutor tenha em vista diz respeito às particularidades do idioma para o qual se traduz, como suas regras de formação de palavras, que podem não permitir a naturalização ${ }^{5}$ de um termo.

No tocante aos textos turísticos, Marqueze (2018) acrescenta à lista de Florin (1993) um quinto aspecto que influencia a maneira como o tradutor irá lidar com referentes culturais: as limitações impostas pelas imagens e pelas edições bilíngues que trazem o texto em determinado idioma na coluna à esquerda, e em outro idioma à direita, restringindo o espaço disponível para o texto traduzido 6 .

Retomando a pergunta feita em 2.1 (Como lidar com referentes culturais lexicais em textos turísticos?), podemos dizer que, tendo os elementos elencados acima em mente, o tradutor deverá, então, lançar mão de diferentes estratégias de tradução para verter os referentes culturais para o texto-meta, como será detalhado na próxima subseção.

\subsection{Estratégias de tradução para referentes}

\section{culturais}

Estratégias de tradução são entendidas aqui como formas explícitas de manipulação textual utilizadas no momento em que o tradutor deve solucionar um problema de tradução, a fim de alcançar uma versão do texto-meta que seja coerente com seu propósito (CHESTERMAN 1997).

Marco (2002) elenca em seu livro El fil d'Ariadna: anàlisi estilística $i$ traducció literária sete estratégias de tradução utilizadas por três tradutores ao verterem Three men in a boat, de J.K Jerome do inglês para o catalão. 0 autor baseia-se na lista de estratégias de tradução para referentes culturais apresentadas por Newmark (1988).

\footnotetext{
${ }^{5}$ Estratégia de tradução que adapta a pronúncia do termo à língua-meta, como, por exemplo, transformar "sambódromo" em "sambadrome" no inglês.

${ }^{6}$ Essa dificuldade imposta ao tradutor de textos turísticos é mencionada também em Kelly (1997), Muñoz (2012) e Merkaj (2013).

TradTerm, São Paulo, v.37, n. 2, janeiro/2021, p. 671-699

Número Especial - Linguística de Corpus www.revistas.usp.br/tradterm
} 
Exibimos abaixo a lista de Marco (2002: 209-210) com exemplos de Marqueze (2018: 25-26):

1) Transferência: processo de transferir uma palavra da língua-fonte para o texto-meta como estratégia de tradução (NeWmark 1988). Como transferir o termo "Festa Junina" para a versão em inglês de um texto turístico, por exemplo: "The Festa Junina is one of the most traditional festivities of the Northeast" (TOURIST GUIDE 2012: 19).

2) Naturalização: quando uma palavra da língua-fonte é adaptada à pronúncia, ortografia e morfologia da língua-meta, como transformar "sambódromo" em "sambadrome".

3) Tradução literal: tradução palavra por palavra, podendo apresentar rearranjos morfossintáticos. É o caso de verter "Bonecos Gigantes” para "Giant Puppets".

4) Neutralização: emprego de um termo livre de carga cultural, que alude à função do referente cultural, como verter "blocos carnavalescos" para "groups".

5) Adição de informação: qualquer adição de informação que auxilie o leitor na compreensão do significado do referente cultural, podendo tratar-se de uma nota de rodapé ou do uso de hiperônimos ou de tradução literal quando combinados à estratégia de transferência, por exemplo. É o caso de verter "frevo" para "frevo dance". 0 termo "dance" aqui é empregado para informar o leitor de que frevo é uma dança, sendo considerado, portanto, adição de informação.

6) Equivalente cultural: uso de um conceito na cultura-meta que seja aproximadamente equivalente ao da cultura-fonte, como verter "quadrilha" para "square dance".

7) Omissão: eliminação dos elementos considerados redundantes ou de pouca importância.

Essas estratégias nos auxiliaram na compreensão e na descrição de como os referentes culturais nos textos turísticos da Embratur foram vertidos do texto-fonte para o texto-meta.

TradTerm, São Paulo, v.37, n. 2, janeiro/2021, p. 671-699

Número Especial - Linguística de Corpus www.revistas.usp.br/tradterm 


\section{Metodologia}

A Linguística de Corpus auxilia este estudo em duas frentes: 1) na extração dos termos cujas traduções foram analisadas e 2) na identificação de como os termos selecionados foram vertidos para o inglês.

0 primeiro passo foi selecionar os textos que deveriam compor o nosso corpus de textos turísticos sobre o Brasil escritos originalmente em português (subcorpus em português) e que tivessem tradução para o inglês (subcorpus em inglês). Trata-se, portanto, de um corpus paralelo, já que é composto por textos originais em um idioma com tradução para outro.

De acordo com Tagnin (2015), um corpus paralelo pode ser utilizado para a) comparar diferentes versões da tradução de um texto, b) para acompanhar o processo de revisão pelo qual a tradução passa, c) para verificar como uma palavra ou expressão já foi traduzida e d) para investigar estratégias de tradução empregadas "em itens por vezes problemáticos" (TAGNIN 2015: 46), como é o caso dos referentes culturais lexicais. Foi, portanto, com a intenção de estudar as estratégias empregadas na tradução de referentes culturais brasileiros que compilamos nosso corpus paralelo.

Como nosso foco eram os textos turísticos publicados pela Embratur, baixamos do site do Ministério do Turismo cinco materiais bilíngues disponíveis para download ${ }^{7}$. Todos foram escritos originalmente em português e apresentam tradução para o inglês, são eles:

1) Guia de Cidades (2012): material que traz informações turísticas sobre cada estado brasileiro e ainda compartilha curiosidades sobre a culinária e a arte brasileiras. Total de palavras do subcorpus em português: 122.982 . Total de palavras do subcorpus em inglês: 108.621

2) Livreto Junino (2013): o material traz informações e curiosidades sobre as principais Festas Juninas brasileiras. Total de palavras do subcorpus em português: 3.009. Total de palavras do subcorpus em inglês: 2.894

\footnotetext{
${ }^{7}$ Até abril de 2020, todos os materiais analisados ainda estavam disponíveis para download no site do Ministério do Turismo: http://www.turismo.gov.br/

TradTerm, São Paulo, v.37, n. 2, janeiro/2021, p. 671-699

Número Especial - Linguística de Corpus www.revistas.usp.br/tradterm
} 
3) Aromas, Cores e Sabores do Brasil (2014): revista que foi distribuída aos jornalistas estrangeiros durante a Copa do Mundo sediada no Brasil em 2014. Contém informações gerais sobre a culinária e festas típicas das cidadessede. Total de palavras do subcorpus em português: 7.356 . Total de palavras do subcorpus em inglês: 7.241.

4) Partiu Brasil! (2015): revista com informações turísticas sobre cada estado brasileiro, separadas por região. Total de palavras do subcorpus em português: 16.556 . Total de palavras do subcorpus em inglês: 13.594

5) Blog Embratur (2016/2020): artigos com informações turísticas dos estados brasileiros. Total de palavras do subcorpus em português: 5.158. Total de palavras do subcorpus em inglês: 5.293

Somente o Guia de Cidades traz o nome da agência responsável pela tradução8. Trata-se de uma agência especializada em traduções de textos técnicos, conforme informação no site da empresa. Os outros materiais nada informam sobre os tradutores ou sobre as agências responsáveis pela tradução dos textos.

Quatro dos cinco materiais estavam disponibilizados em .pdf. Dessa forma, foi necessário convertê-los para .txt, uma vez que o software de análise linguística utilizado nesta pesquisa lê textos apenas nesse último formato. Para isso, utilizamos o $A B B Y Y$ Fine Reader, programa que faz o reconhecimento óptico de caracteres (do inglês optical character recognition, OCR), convertendo arquivos em .pdf e documentos digitalizados em dados editáveis.

O Blog Embratur é o único material que não estava em .pdf. Tudo o que tivemos que fazer foi copiar as passagens relacionadas a turismo no Brasil e colar diretamente no arquivo em .txt.

Feita a conversão dos textos de .pdf para .txt e corrigidos os erros decorrentes da conversão dos arquivos, nosso subcorpus em português totalizou 154.984 palavras, enquanto o subcorpus em inglês totalizou 137.643 palavras.

\footnotetext{
${ }^{8}$ Entramos em contato com a empresa para sabermos da possibilidade de conduzirmos uma entrevista com os tradutores responsáveis pelo Guia de Cidades, mas não tivemos resposta.

TradTerm, São Paulo, v.37, n. 2, janeiro/2021, p. 671-699

Número Especial - Linguística de Corpus www.revistas.usp.br/tradterm
} 
O próximo passo foi extrair os termos para análise. Para tanto, submetemos nosso subcorpus em português à análise semiautomática com a Keyword List do programa AntConc, como detalharemos a seguir.

\subsection{AntConc}

O AntConc é um software de análise linguística de acesso gratuito criado em 2002 por Lawrence Anthony, professor na Faculty of Science and Engineering na Universidade de Waseda, Japão.

Dentre suas principais ferramentas, citamos a Word List, que gera a lista de todas as palavras do corpus em estudo; a Keyword List, que permite a extração de palavras-chave; a ferramenta Concordance, que gera linhas de concordância; Collocates, que oferece uma lista de colocados da palavra de busca e, por fim, a ferramenta Clusters/N-Grams, que exibe agrupamentos de palavras com base no termo de busca, permitindo a identificação de lexias complexas no corpus.

Para esta pesquisa, as ferramentas que nos auxiliaram na extração dos termos para análise foram a Keyword list e a Clusters/N-Grams, como veremos a seguir.

\subsubsection{Extração dos termos de análise}

A ferramenta Keyword List exibe as palavras mais representativas de um corpus, sendo elas o resultado da comparação da lista de palavras do corpus de estudo com a de um corpus de referência (TAGNIN 2015). Esse último deve ser, pelo menos, entre três e cinco vezes maior que o corpus de estudo, pois, segundo Berber Sardinha (2004), um corpus de referência que tenha, no mínimo, essas dimensões irá gerar mais palavras-chave do que corpora menores. Dessa forma, as palavras que têm, nos dois corpora, frequências estatisticamente semelhantes, irão desaparecer. A lista de palavras-chave trará, portanto, somente aquelas palavras que forem características do corpus de estudo.

No caso desta pesquisa, nosso objetivo era extrair referentes culturais lexicais brasileiros do nosso corpus de textos turísticos. Assim, utilizamos como

TradTerm, São Paulo, v.37, n. 2, janeiro/2021, p. 671-699 Número Especial - Linguística de Corpus www.revistas.usp.br/tradterm 
corpus de referência o corpus de língua portuguesa geral Lácio-Ref, do projeto Lácio-Web9.

Depois de inserirmos o corpus de referência no AntConc junto com nosso corpus de estudo, geramos a lista de palavras-chave, que totalizou 10.327 tokens (palavras em geral) e 2.118 types (palavras diferentes). Como previsto, as palavras-chave eram, em sua maioria, pertencentes ao campo lexical do turismo e da cultura brasileira, como pode ser visto na Figura 1, onde destacamos em vermelho, na posição 120, o primeiro referente cultural brasileiro encontrado no corpus de estudo.

Figura 1: Pesquisa de palavras-chave no AntConc 3.5.8.

$\begin{array}{|lllll|}\text { Rank } & \text { Freq } & \text { Keyness } & \text { Effect } & \text { Keyword } \\ 104 & 62 & +365.41 & 0.0011 & \text { só } \\ 105 & 79 & +365.09 & 0.0013 & \text { areia } \\ 106 & 60 & +353.63 & 0.001 & \text { reúne } \\ 107 & 81 & +351.1 & 0.0014 & \text { barco } \\ 108 & 66 & +348.33 & 0.0011 & \text { cachoeiras } \\ 109 & 62 & +347.83 & 0.0011 & \text { trilhos } \\ 110 & 59 & +347.73 & 0.001 & \text { baía } \\ 111 & 59 & +347.73 & 0.001 & \text { pé } \\ 112 & 65 & +342.61 & 0.0011 & \text { banhos } \\ 113 & 58 & +341.84 & 0.001 & \text { dança } \\ 114 & 58 & +341.84 & 0.001 & \text { espaço } \\ 115 & 58 & +341.84 & 0.001 & \text { extensão } \\ 116 & 58 & +341.84 & 0.001 & \text { prática } \\ 117 & 58 & +341.84 & 0.001 & \text { áreas } \\ 118 & 57 & +335.94 & 0.001 & \text { turístico } \\ 119 & 109 & +333.79 & 0.0018 & \text { visita } \\ 120 & 68 & +330.82 & 0.0012 & \text { pantanal } \\ 121 & 56 & +330.05 & 0.001 & \text { indígenas }\end{array}$

Os referentes culturais foram selecionados manualmente, conforme as palavras-chave eram exploradas uma a uma. Salientamos que, além dos termos simples, precisamos considerar os termos complexos por justaposição com e sem hífen, como "boi-bumbá” e "Festa Junina”, respectivamente. Para isso, usamos a ferramenta Clusters/N-Grams. Um exemplo de como esse rastreio se deu está ilustrado nas Figuras 2 e 3, abaixo. A Figura 2 mostra "festas" na posição 77 da lista de palavras-chave.

\footnotetext{
9 O Lácio-Web foi um projeto do NILC (Núcleo Interinstitucional de Linguística Computacional) em parceria com a FFLCH (Faculdade de Filosofia, Letras e Ciências Humanas), financiado pelo CNPq, com início em 2002 e duração de 30 meses. 0 projeto disponibilizou gratuitamente na Web vários corpora do português contemporâneo e ferramentas linguístico-computacionais. Para saber mais: http://143.107.183.175:22180/lacioweb/index.htm. Último acesso em 28 de abr. de 2020.
}

TradTerm, São Paulo, v.37, n. 2, janeiro/2021, p. 671-699 Número Especial - Linguística de Corpus www.revistas.usp.br/tradterm 
Figura 2: Posição de "festas" na lista de palavras-chave no AntConc 3.5.8.

\begin{tabular}{|c|c|c|c|c|}
\hline Rank & Freq & Keyness & Effect & Keyword \\
\hline Oర & 140 & $+4 y / .14$ & U.UU $\angle 0$ & avenuad \\
\hline 69 & 84 & +495.09 & 0.0014 & através \\
\hline 70 & 84 & +495.09 & 0.0014 & várias \\
\hline 71 & 81 & +477.41 & 0.0014 & espécies \\
\hline 72 & 123 & +475.92 & 0.0021 & diariamente \\
\hline 73 & 93 & +474.81 & 0.0016 & cachoeira \\
\hline 74 & 81 & +466.71 & 0.0014 & gastronomia \\
\hline 75 & 144 & +466.34 & 0.0024 & transporte \\
\hline 76 & 78 & +459.72 & 0.0013 & aniversário \\
\hline 77 & 104 & +457.25 & 0.0018 & festas \\
\hline 78 & 77 & +453.83 & 0.0013 & época \\
\hline 79 & 75 & +442.04 & 0.0013 & tềm \\
\hline 80 & 95 & +436.81 & 0.0016 & aeroporto \\
\hline 81 & 74 & +436.15 & 0.0013 & típicos \\
\hline 82 & 130 & +430.32 & 0.0022 & festa \\
\hline 83 & 73 & +430.25 & 0.0012 & atração \\
\hline 84 & 73 & +430.25 & 0.0012 & típica \\
\hline 85 & 115 & +424.13 & 0.0019 & serra \\
\hline os & Anen & - $\operatorname{Ann} 01$ & n nase & Ann \\
\hline
\end{tabular}

Apesar de o termo "festas" em si não tratar de um referente cultural, pressupomos que uma busca por ele na ferramenta Clusters/N-Grams do AntConc revelaria lexias complexas que, por sua vez, poderiam configurar referentes culturais. A Figura 3 ilustra a busca por "festas" na referida ferramenta, onde definimos o cluster size para o mínimo de 2 e o máximo de 4 palavras com o termo de busca à esquerda, o que gerou uma lista por ordem de frequência de 244 ocorrências. 
Figura 3: Busca por "festas" na ferramenta Clusters/N-Grams

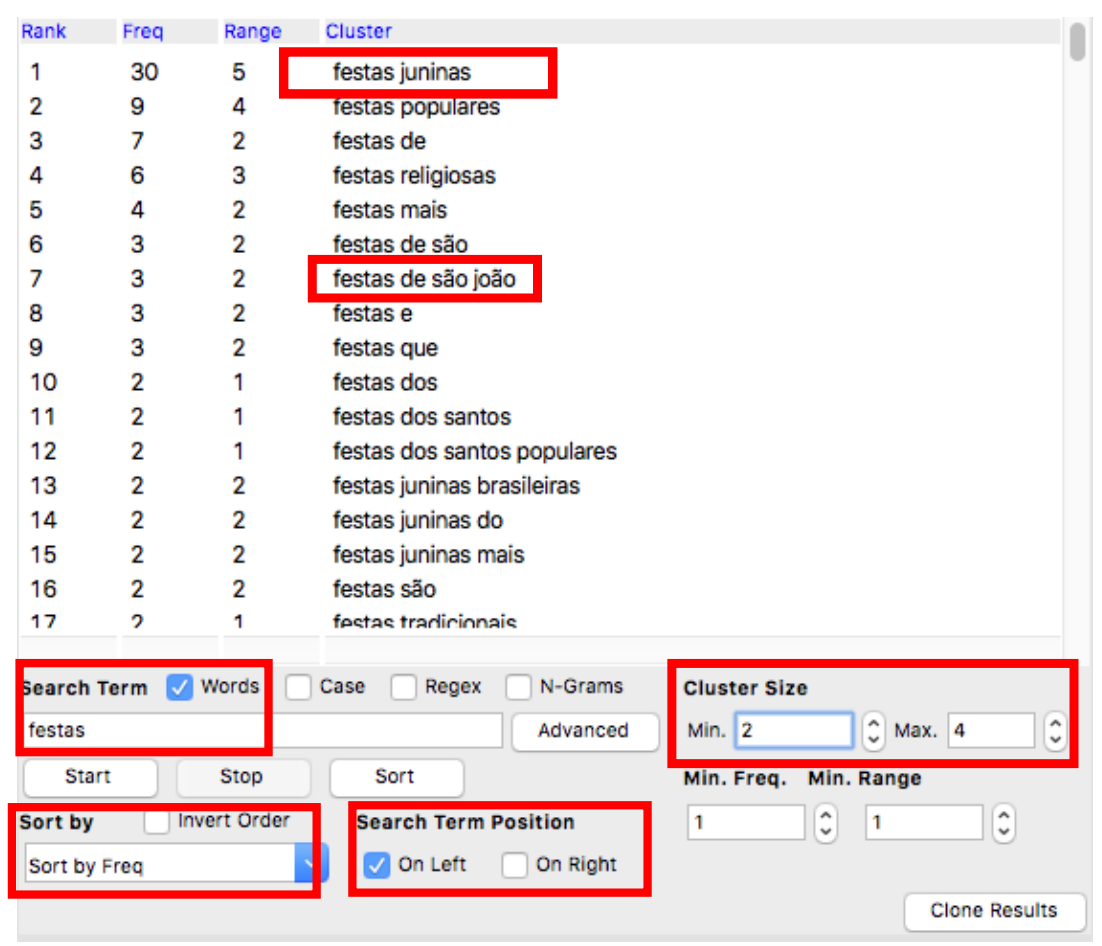

Como pode ser visto, já na primeira e na sétima posições encontramos os termos "Festas Juninas" e "Festas de São João", respectivamente.

Os termos candidatos à análise foram selecionados de acordo com as cinco categorias de referentes culturais propostas por Newmark (1988):

1) Ecologia: flora, fauna, montanhas e fenômenos da natureza;

2) Cultura material: culinária, vestuário, arquitetura e transporte;

3) Cultura social: atividades de trabalho e lazer, como profissões, modos de trabalho, danças, músicas e festas;

4) Organizações, instituições, procedimentos e conceitos de teor político e administrativo, religioso e artístico;

5) Gestos e hábitos: como as pessoas de diferentes culturas se comportam em determinadas situações, como, por exemplo, as maneiras como se cumprimentam (aperto de mão, beijo no rosto etc.).

A fim de eliminarmos a subjetividade da busca manual e validarmos os termos candidatos à análise como próprios do Brasil, os confrontamos em três obras sobre a cultura do país: Brasil: Almanaque de Cultura Popular (ANDREATO;

TradTerm, São Paulo, v.37, n. 2, janeiro/2021, p. 671-699 Número Especial - Linguística de Corpus www.revistas.usp.br/tradterm 
Rocha 2009), Folclore Brasileiro (Megale 2011) e O Dicionário do Folclore Brasileiro (CASCUDO 2012). Para que fossem confirmados como típicos do país, os termos deveriam constar em, pelo menos, duas das três obras selecionadas.

Após esse procedimento, obtivemos um total de 70 termos para análise, os quais estão separados abaixo, conforme as categorias de Newmark (1988). Como "gestos e hábitos" são comumente descritos através de linguagem não cultural (NEWMARK 1988), não foi encontrado em nosso corpus nenhum referente cultural para esta categoria.

1) Ecologia: caatinga, cerrado, Chapada Diamantina, Chapada dos Guimarães, Chapada dos Veadeiros, Lençóis Maranhenses, Pantanal;

2) Cultura material: acarajé, azeite de dendê, barreado, cachaça, canjica, caipirinha, caruru, chimarrão, cuscuz, curau, farofa, feijão tropeiro, feijoada, jambu, maniçoba, moqueca, paçoca, pamonha, pé de moleque, picadinho, pirão, quentão, rapadura, tacacá, tapioca, tererê, tucupi, vatapá. Abadá. Arraial, bumbódromo, sambódromo;

3) Cultura social: Carnaval, Cavalhada(s), Círio de Nazaré, Bumba meu boi, Festa(s) Junina(s), Festa(s) de São João, Festa do Divino (Espírito Santo), Festival Folclórico de Parintins, Procissão do Fogaréu. Axé, baião, boibumbá, carimbó, forró, frevo, marchinha(s), quadrilha(s), samba, sambaenredo, tambor-de-crioula, xote, xaxado;

4) Organizações, instituições, procedimentos e conceitos de teor político e administrativo, religioso e artístico: (Boi) Caprichoso, (Boi) Garantido, Boneco(s) Gigante(s)/Boneco(s) de Olinda, bloco(s) (de rua), escola(s) de samba, trio(s) elétrico(s), lansã, lemanjá, Xangô.

Após o levantamento desses termos, analisamos suas traduções utilizando o programa AntPconc.

\subsubsection{AntPconc e análise dos termos selecionados}

- AntPconc é um concordanciador de corpora paralelos de acesso gratuito e de fácil manipulação, desenvolvido por Laurence Anthony em 2014. 
Para que o pesquisador possa explorar seu corpus nesse programa, cada linha do texto escrito no idioma original deverá coincidir com a linha de sua tradução. Desse modo, o alinhamento precisará ser feito manualmente pelo pesquisador caso as linhas de ambos os textos não coincidam, como ocorreu neste trabalho. Ao buscarmos um termo no programa, uma janela se abre e todas as suas ocorrências no idioma original são exibidas em sua parte superior e cada linha correspondente no texto traduzido é exibida na parte inferior, como ilustrado na Figura 2. Convém ressaltar que a busca pela tradução do termo em análise não é feita automaticamente pelo programa, mas sim de forma manual pelo(a) pesquisador(a).

Figura 2: Pesquisa do termo "quadrilha" no AntPconc.

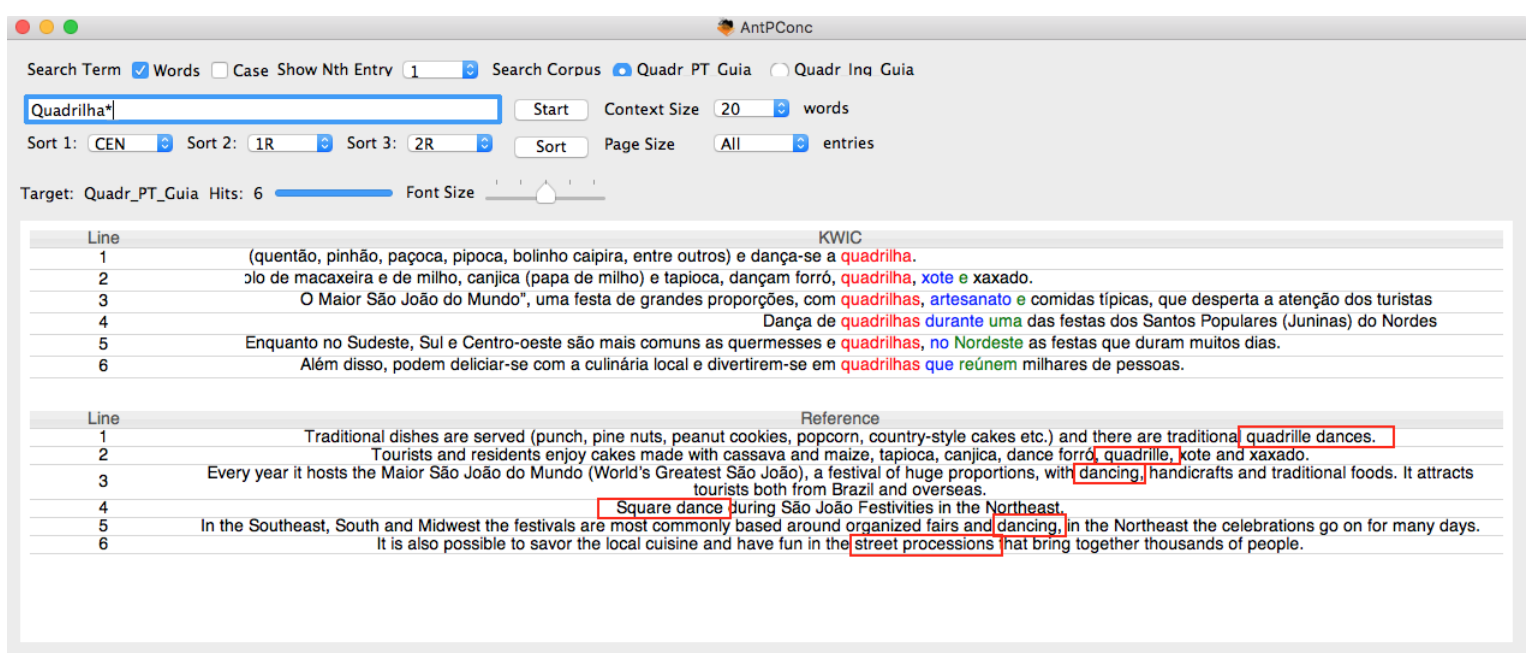

Depois de levantarmos as estratégias de tradução empregadas a cada termo selecionado, refletimos sobre sua adequação dentro do contexto dos textos turísticos, como mostra a próxima seção.

\section{Discussão}

Esta seção está dividida por estratégias de tradução, como as elencadas por Marco (2002), com exceção das estratégias de naturalização e omissão, por nos faltarem ocorrências significativas. Para cada estratégia oferecemos alguns dos exemplos mais intrigantes encontrados durante análise do nosso corpus no AntPconc.

TradTerm, São Paulo, v.37, n. 2, janeiro/2021, p. 671-699 Número Especial - Linguística de Corpus www.revistas.usp.br/tradterm 


\subsection{Transferência}

A transferência foi a estratégia de tradução mais detectada em nosso corpus. Apesar de manter a brasilidade do termo, é importante que haja uma reflexão cuidadosa por parte do tradutor sobre a real necessidade de se transferir o referente cultural para o texto-meta - caso não haja espaço para adição de informação - a fim de não sobrecarregar o leitor com conceitos que desconhece, o que poderá resultar em quebra de comunicação.

A passagem sobre pratos típicos do Norte do país na revista Aromas, Cores e Sabores do Brasil é um exemplo. O texto em português informa que a maniçoba é a "feijoada do Pará" e explica do que é composta. Para os brasileiros, que conhecem uma feijoada, essa passagem não traz problemas. Ainda que não conheçamos o prato paraense, teremos uma ideia do que se trata ao lermos a comparação entre os dois pratos. No texto em inglês, o termo "feijoada" foi transferido, resultando em "maniçoba (the feijoada from Pará)"; no entanto, ao analisarmos o arquivo em .pdf da revista, vemos uma explicação sobre a feijoada somente cinco páginas adiante. Dessa forma, a passagem sobre a culinária do Norte que, linhas antes de mencionar a maniçoba, traz nomes de pratos e ingredientes como “tacacá”, “tucupi” e “jambú” sem nenhuma adição de explicação, só contribui para dificultar ainda mais o entendimento do leitor estrangeiro sobre os pratos típicos da região que, em vez de se tornarem atrativos, resultam apenas em uma lista de termos incompreensíveis para ele. Aqui retomamos a observação de se dosar a quantidade de informação ofertada ao leitor estrangeiro para que a função apelativa dos textos turísticos não seja prejudicada e, ainda, de entender a importância do referente cultural no contexto. No texto em questão, a explicação “feijoada from Pará” não contribui para o entendimento do leitor estrangeiro sobre a "maniçoba", podendo, assim, ser omitida no texto-meta, já que, em seguida, há uma explicação sobre os ingredientes que compõem o prato.

Um outro exemplo na mesma revista é a passagem sobre como preparar um quentão. O primeiro parágrafo do texto-fonte informa que o quentão é feito com cachaça nas regiões Norte e Nordeste do Brasil. Essa informação é vertida para o texto-meta com a manutenção do termo "cachaça” em português. Porém, no parágrafo do texto-fonte onde é explicado como o quentão é feito,

TradTerm, São Paulo, v.37, n. 2, janeiro/2021, p. 671-699 Número Especial - Linguística de Corpus www.revistas.usp.br/tradterm 
o termo "pinga” substitui “cachaça”: “Leve ao fogo todos os ingredientes, menos a pinga, e deixe ferver até soltar o sabor. Tire do fogo e acrescente a pinga." Essa substituição é mantida no texto-meta, resultando em: "Take all ingredients, except for the pinga, to the fire and let it boil until it releases the flavor. Remove it from the fire and add the pinga." Mais uma vez podemos afirmar que um brasileiro entenderia o texto sem grandes problemas. Não podemos dizer o mesmo do leitor-meta. Ainda que "cachaça" seja hoje um termo dicionarizado em língua inglesa, ele dificilmente irá relacioná-lo à “pinga” sem que haja nenhuma adição de informação.

\subsection{Tradução literal}

Nas análises do material da Embratur, o emprego da tradução literal em determinados trechos resultou, seguramente, em um texto de difícil compreensão para o leitor-meta. Em relação a essa estratégia, nosso foco não é o referente cultural em si, mas o que se diz sobre ele.

É o caso do texto sobre o quentão mencionado acima, onde o caráter polissêmico do termo "cravo" em português levou o tradutor ao erro" ao empregar a estratégia de tradução literal. Na lista de ingredientes, "cravo" foi traduzido para "harpsichord”, que é, na verdade, o instrumento de mesmo nome e não a especiaria, que em inglês é clove ${ }^{11}$. Uma pesquisa um pouco mais cuidadosa teria evitado tal erro.

Ainda sobre a tradução literal, mencionamos uma passagem no Guia de Cidades que discorre brevemente sobre as festas típicas do Ceará.

A passagem no texto-fonte explica que os turistas vão às Festas de São João em busca de comidas e atrações “típicas dessa época do ano”, sem especificar, porém, que época é essa. Para o leitor brasileiro, essa passagem é compreensível, já que sabe em que mês essas festas ocorrem. O mesmo não é verdade para o leitor do texto-meta, onde se lê: "The São João festivities in Ceará attract large numbers of tourists in search of food and fun typical of this

\footnotetext{
${ }^{10}$ Erro, de acordo com Cruces Colado (2001), é a ruptura das regras de coerência de um texto-meta, sejam gramaticais, lexicais, semânticas ou culturais.

${ }^{11}$ Rebechi (2015) também menciona essa ocorrência na revista da Embratur em sua tese de doutorado sobre a culinária brasileira.
}

TradTerm, São Paulo, v.37, n. 2, janeiro/2021, p. 671-699

Número Especial - Linguística de Corpus www.revistas.usp.br/tradterm 
time of year" (grifo nosso). Para o leitor-meta, que muito provavelmente não sabe em que época essas festas são realizadas, a adição dessa informação fazse necessária para que o texto cumpra a função de atraí-lo para a festa em questão.

\subsection{Equivalente cultural}

O emprego da estratégia de equivalência cultural apontou para a perda da brasilidade dos termos em análise. Porém, quando aplicada como adição de informação de um referente cultural, pode auxiliar o leitor-meta na compreensão de um termo cujo conceito está longe de sua realidade.

É o que ocorre em uma passagem no Livreto Junino que discorre sobre um concurso de quadrilha. Ao transferir o termo "Concurso de Quadrilhas Juninas" para o texto-meta, o tradutor adiciona entre parênteses "Contest of June Square Dance Groups". A "square dance” americana é muito semelhante às quadrilhas juninas, mas não possui alguns dos elementos próprios da dança brasileira, como a encenação de um casamento na roça, por exemplo. Portanto, o leitor-meta que conhece a dança americana terá uma ideia aproximada de como é a brasileira.

Esse não é o caso de uma passagem da revista Aromas, Cores e Sabores do Brasil sobre os trios elétricos, onde esse referente cultural é vertido para o texto-meta como "bandwagons". Segundo os dicionários de língua inglesa Oxford, Cambridge e Collins, o termo "bandwagons" refere-se às bandas, como as de circo, que são colocadas em cima de um carrinho para tocar em desfiles e cortejos. 0 equivalente cultural empregado não apenas elimina a brasilidade do termo como não dá conta de transmitir ao leitor-meta a grandeza desse referente cultural que, ao contrário das pequenas bandas de circo, junta multidões ao seu redor, sendo um importante símbolo do carnaval brasileiro.

A equivalência cultural também é empregada de maneira questionável no Blog Embratur em uma lista dos ingredientes do quentão. Enquanto o textofonte explica que a bebida é feita com "cravo e cachaça", no texto-meta é informado que a bebida é feita com "clove and rum", o que elimina seu caráter típico, transformando nosso quentão em outra bebida.

TradTerm, São Paulo, v.37, n. 2, janeiro/2021, p. 671-699 Número Especial - Linguística de Corpus www.revistas.usp.br/tradterm 


\subsection{Neutralização}

Em uma das ocorrências de "arraial" na revista Aromas, Cores e Sabores do Brasil, o termo está inserido no nome da maior Festa Junina de Belo Horizonte, o Arraial de Belô. No texto-meta, "arraial" foi neutralizado para "fair"12, resultando em Belô Fair. Porém, não manter o nome da festa em português certamente irá contra o objetivo de atrair o turista para o evento promovido. Um turista estrangeiro que avisa ao taxista que gostaria de ser levado à "Belô Fair" corre o risco de não chegar ao lugar desejado.

Um emprego da estratégia de neutralização que pareceu muito útil aos tradutores dos textos analisados foi quando não havia espaço suficiente para fornecer mais explicações sobre um referente cultural, mas mantê-lo também não seria uma opção, pois prejudicaria o entendimento do texto-meta. Um exemplo é a neutralização de "Festa de São João" em uma passagem muito curta na revista Partiu Brasil. 0 texto-fonte informa que na Praia do Atalaia, em Aracaju, "acontece o Arraial do Povo, a tradicional festa de São João". No texto-meta, lemos que essa praia é "home to Arraial do Povo, a traditional feast in celebration of Saint John 13". A neutralização de "festa de São João" para "festa em honra a São João" informa o leitor sobre o que é o "Arraial do Povo" sem sobrecarregá-lo com mais um referente cultural.

\subsection{Adição de informação}

A estratégia de adição de informação se mostra muito útil quando é possível ao tradutor lançar mão dela sabendo dosar o que vale ou não ser explicitado ao leitor-meta. Cumpre ressaltarmos, no entanto, que, para que essa estratégia tenha o resultado esperado, é necessário que o tradutor conheça bem o referente cultural com o qual está lidando e a informação a ser oferecida sobre ele. É o caso, por exemplo, de verter "forró, baião e xote" para "regional dances such as forró, baião and xote" ${ }^{14}$, como mostra uma passagem do Guia de Cidades sobre as Festas Juninas no Nordeste.

\footnotetext{
${ }^{12}$ Feira.

${ }^{13}$ Festa tradicional em honra a São João (tradução nossa).

14 "Danças regionais, como forró, baião e xote" (tradução nossa).

TradTerm, São Paulo, v.37, n. 2, janeiro/2021, p. 671-699

Número Especial - Linguística de Corpus www.revistas.usp.br/tradterm
} 
Por outro lado, ao não conhecer o referente cultural, o tradutor poderá apresentar uma informação equivocada, como se deu em uma passagem no Guia de Cidades sobre o "bumbódromo" em Parintins (AM), local onde ocorre o festival folclórico que leva o nome da cidade. No texto-fonte já há uma explicação sobre o lugar, onde lemos que o bumbódromo é "um tipo de estádio com formato de cabeça de boi estilizada". No entanto, é possível que o tradutor tenha julgado essa explicação como insuficiente para o leitor-meta, pois optou por mudá-la no texto-meta, informando que o local trata de um "stadium for bumba meu boi festivities"15. Destacamos, porém, que a brincadeira de boi que acontece no Norte do Brasil é chamada "boi-bumbá" e não "bumba meu boi". Enquanto esta é uma festa de rua celebrada em vários estados do Nordeste brasileiro, sendo o estado do Maranhão seu principal representante, aquela possui traços próprios do Norte, como a incorporação de elementos da Floresta Amazônica à lenda da morte e ressurreição de um boi, lenda essa que é comum a ambas. Enquanto o bumba meu boi do Maranhão possui o título de Patrimônio Cultural do Brasil pelo Instituto do Patrimônio Histórico e Artístico Nacional (IPHAN), o boi-bumbá tem Parintins como sua Capital Nacional. Compreender as diferenças entre essas brincadeiras de boi, portanto, se faz necessário para o fornecimento de uma informação precisa.

\section{Considerações finais}

Recorrer à Teoria Funcionalista da Tradução para a análise das estratégias de tradução empregadas em referentes culturais nos textos turísticos da Embratur nos ajudou a lançar luz sobre os desafios com os quais os tradutores desses textos devem lidar e o alto grau de reflexão exigido no momento de traduzir as passagens onde os referentes culturais estão inseridos, o que está longe de ser uma tarefa simples. Afinal, o excesso de termos irreconhecíveis para o leitor-meta, falta de explicações e informações inconsistentes podem impedir o cumprimento do propósito desses textos de angariar turistas estrangeiros para o país.

\footnotetext{
${ }^{15}$ Estádio para as festas de bumba meu boi.

TradTerm, São Paulo, v.37, n. 2, janeiro/2021, p. 671-699 Número Especial - Linguística de Corpus www.revistas.usp.br/tradterm
} 
Para que o tradutor de textos turísticos consiga fazer a escolha mais adequada dentre as várias estratégias a seu dispor, faz-se necessária uma reflexão cuidadosa acerca dos referentes culturais, tendo em vista os pontos propostos na seção 2.2: a) as funções principais e secundárias do texto-meta; b) o quanto o leitor-meta está familiarizado com os referentes culturais; c) a importância dos referentes culturais na passagem a ser traduzida; d) as características particulares dos idiomas envolvidos; e, por fim, e) as limitações impostas pelas imagens e pelo espaço, que devem coincidir em edições bilíngues, o que exigirá do tradutor a priorização de certas informações em detrimento de outras.

Dessa forma, o texto-fonte é exatamente o que seu nome indica: fonte primária de informações para que o tradutor, com base nelas e na função do texto-meta, produza um outro texto para a cultura para a qual se traduz. Consequentemente, determinadas estratégias serão mais ou menos apropriadas. Uma avaliação desse tipo poderia ter evitado alguns dos problemas encontrados nas traduções analisadas, os quais, muito provavelmente, dificultaram o cumprimento do propósito dos textos-meta, como recapitularemos brevemente nos parágrafos a seguir.

Retomemos a passagem da revista Aromas Cores e Sabores do Brasil e a do Blog Embratur onde, respectivamente, o termo "cachaça” foi vertido para "rum" e "trios elétricos" para "bandwagons". Essas ocorrências demonstram o que Nord (1991, 1997, 2007) chama de “enganar” o leitor, visto que, ao pedir quentão em uma Festa Junina, o turista não encontrará rum entre os ingredientes da bebida. Da mesma forma que, ao chegar no carnaval em Salvador, o turista não deparará com carros com bandas de circo, mas com algo de proporções muito maiores. Nesses casos - e aqui também incluímos a ocorrência do termo "Belô Fair" - Nord (1991) explica que essas ações comunicativas estão baseadas em premissas falsas, e que seria equivocado, portanto, dizer que os textos-meta em questão são funcionais. Resgatamos aqui também o conceito de lealdade da autora para salientar que essa lealdade não se deve apenas para com o leitor do texto-meta, que não deve ser "enganado" pelo texto, mas também para com o autor do texto-fonte, que confia que o 
texto-meta será bem-sucedido na sua função de atrair o turista para conferir os referentes culturais divulgados.

Além disso, erros de tradução, como verter "cravo" (a especiaria) para "harpsichord" (o instrumento) e a oferta de informações confusas, ininteligíveis e errôneas projetam no exterior uma imagem de amadorismo do Brasil, o que vai na contramão dos esforços empreendidos para o fortalecimento da nossa indústria turística ${ }^{16}$. Ressaltamos aqui que esses textos foram produzidos dentro do âmbito da Embratur, autarquia do Ministério do Turismo que cuida da promoção turística do Brasil no exterior.

A análise dos textos da Embratur nos mostra que a tradução de textos turísticos não é tarefa fácil. No entanto, acreditamos que as dificuldades inerentes a eles são atenuadas quando o tradutor compreende as suas peculiaridades e quando está munido de uma teoria que os ampara no momento de eleger a melhor estratégia de tradução, como mostramos durante este trabalho. Do mesmo modo, uma reflexão sobre as estratégias de tradução já utilizadas em textos turísticos e sobre suas possíveis implicações na funcionalidade do texto-meta deve favorecer uma prática tradutória mais consciente. Este trabalho pode ser feito em cursos de treinamentos para tradutores, por exemplo.

Em tempo, aproveitamos para destacar que as estratégias de Marco (2002) são passíveis de auxiliar tanto alunos quanto professores de cursos de tradução. Não como uma lista prescritiva de estratégias de tradução das quais os tradutores devem lançar mão; afinal, outros tratamentos podem ser dados a referentes culturais, obviamente. Mas, como aponta Costa (2006), uma lista de estratégias serve como forma de conscientização do que é possível ser feito quando esses profissionais encontram um desafio de tradução, o que os ajuda a aperfeiçoar sua prática tradutória.

Assim sendo, acreditamos que uma maior conscientização dos tradutores de seu papel como mediadores culturais, a oferta de aulas de tradução focadas em textos turísticos e uma maior divulgação desses textos como detentores de uma linguagem complexa que exigem dos tradutores um alto grau de

\footnotetext{
${ }^{16}$ Essa imagem de amadorismo em textos turísticos também foi alvo de críticas de Costa (2006).

TradTerm, São Paulo, v.37, n. 2, janeiro/2021, p. 671-699 Número Especial - Linguística de Corpus www.revistas.usp.br/tradterm
} 
conhecimento das culturas envolvidas e habilidade de conduzir pesquisas minuciosas sobre conceitos, termos e informações desconhecidos, os textos turísticos poderão ser vistos com a devida seriedade e alcançarão o nível de excelência em tradução que merecem, contribuindo para uma divulgação internacional de qualidade do nosso país, que é o que precisaremos para quando a crise atual passar.

TradTerm, São Paulo, v.37, n. 2, janeiro/2021, p. 671-699

Número Especial - Linguística de Corpus

www.revistas.usp.br/tradterm 


\section{Referências}

ANDREATO, E.; RochA, J. Brasil: almanaque de cultura popular. Rio de Janeiro: Ediouro, 2009. 256 p.

ANTHONY, L. Developing AntConc for a new generation of corpus linguists. In: Corpus linguistics conference, 2013, Lancaster. Proceedings. Lancaster: Lancaster University, 2013. p. 14 - 16.

Berber Sardinha, T. Linguística de Corpus. São Paulo: Manole, 2004.

CASCUDO, L. C. Dicionário do Folclore Brasileiro. 12. ed. São Paulo: Global, 2012. $765 \mathrm{p}$.

COSTA, A. T. P. Brasil mostrando a sua cara: estratégias de tradução no material de divulgação cultural: um estudo baseado em corpus. 2006. $233 \mathrm{f}$. Dissertação (Mestrado) - Curso de Linguística Aplicada, Departamento de Línguas Estrangeiras e Tradução, Universidade de Brasília, Brasília, 2006.

CRUCES Colado, S. El origen de los errores en traducción. In: Domingo, P.; GONZALEZ, E. R. R.; DOLORES, J. P. (coord.), Écrire, traduire et représenter la fête. Valencia: Universitat de València. 2001 p. 813-822.

Chesterman, A. Teaching Strategies for Emancipatory Translation. In: SCHÄFFNER, C.; ADAB, B. (Ed.). Developing Translation Competence. Amsterdam: John Benjamins, 2000. p. 77-89.

FLORIN, S. Realia in translation. In: Zlateva, Palma (Ed.). Translation as social action: Russian and Bulgarian Perspectives. London: Routledge, 1993. p. 122-128.

KELLY, D. The translations of texts from the tourist sector: textual conventions, cultural distance and other constraints. Trans: Revista de Traductología, Málaga, v. 2, p.33-42, 1997.

MARco, J. El fil d'Ariadna: Anàlisi Estilística i Traducció literària. Vic: Eumo Editorial, 2002. $331 \mathrm{p}$.

MARqueze, G. M. C. Proposta de um vocabulário bilíngue de festas populares brasileiras baseada em um estudo de corpus. 2018. 202 f. Dissertação (Mestrado) - Curso de Letras, Letras Modernas, Universidade de São Paulo, São Paulo, 2018. Disponível em: <http: / / www.teses.usp.br/teses/disponiveis/8/8160/tde-14022019105827/fr.php>. Acesso em: 30 abr. 2020.

Megale, N. B. Folclore Brasileiro. 5. Ed. Petrópolis: Vozes, 2011. 169p. 
MERKAJ, L. Tourist communication: a specialized discourse with difficulties in translation. European Scientific Journal, Açores, v. 2, p.321-325, dez. 2013.

MUÑOz, I. D. Analysing common mistakes in translations of tourist texts (Spanish, English and German). Onomázein, Málaga, v. 2, n. 23, p.335-349, 2012.

Newmark, P. A textbook of translation. Hertfordshire: Prentice Hall International,1988. $311 \mathrm{p}$.

NoRD, C. Scopos, Loyalty, and Translational Conventions. Target International Journal of Translation Studies, [s.l.], v. 3, n. 1, p.91-109, 1 jan. 1991. John Benjamins Publishing Company.

NoRD, C. Translating as a Purposeful Activity: Functionalist Approaches Explained. Amsterdam: St. Jerome Publishing, 1997. $154 \mathrm{p}$

NoRD, C. Text analysis in Translation: theory, methodology, and didactic application. 2. ed. Amsterdam: Rodopi, 2005. 274 p. Tradução de Christiane Nord e Penelope Sparrow do livro em alemão de 1988. 202p.

NoRD, C. Function plus loyalty: ethics in Professional Translation. Génesis: Revista Científica do ISAG, Porto, p.7-17, 2007.

PIERINI, P. Quality in Web Translation: An Investigation into UK and Italian Tourism Web Sites. Jostrans: The Journal of Specialised Translation, Londres, v. 8, p.85-103, 2007.

REBECHI, R. R. A tradução da culinária típica brasileira para o inglês: um estudo sob o enfoque da Linguística de Corpus. 2015. 393 f. Tese (Doutorado) Curso de Estudos Linguísticos e Literários em Inglês, Departamento de Letras Modernas, Universidade de São Paulo, São Paulo, SP.

ReISS, K.; Vermeer, H. J. Fundamentos para una teoría funcional de la traducción. Madrid: Ediciones Akal, 1996. 206 p. Tradução de Sandra García Reina e Celia Martín de León da edição em alemão de 1991.

REISS, K. Type, kind and individuality of text: decision making in translation, 1971. In: VENUTI, L. (Ed.). The translation studies reader. London: Routledge, 2000. Cap. 12. p. 160-171.

SNELL-HORNBY, M. Communicating in the Global Village: on language, translation and cultural identity. Current issues in language and society, [s.l.], v. 6, n. 2, p.103-120, abr. 1999. Informa UK Limited.

TAGNIN, S. E. O. A Linguística de Corpus na e para a Tradução. In: TAGNIN, S. E. O.; VIANA, V. (Org.). Corpora na Tradução. São Paulo: Hub Editorial, 2015. p. 19-56.

TradTerm, São Paulo, v.37, n. 2, janeiro/2021, p. 671-699

Número Especial - Linguística de Corpus

www.revistas.usp.br/tradterm 
Recebido em: 30/04/2020

Aceito em: 25/05/2020

Publicado em janeiro de 2021 